\title{
Identifying Potential Social Impact of Collaborative Systems at Design Time
}

\author{
Clarissa Maria de A. Barbosa ${ }^{1}$, Raquel Oliveira Prates ${ }^{2}$, \\ and Clarisse Sieckenius de Souza ${ }^{1}$ \\ ${ }^{1}$ SERG - Departamento de Informática - PUC-Rio, \\ R. Marquês de São Vicente, 225, Gávea, Rio de Janeiro - RJ \\ ${ }^{2}$ Departamento de Ciência da Computação - UFMG, \\ Av. Antônio Carlos, 6627, Prédio do ICEx, sala 4010, Belo Horizonte - MG \\ \{cbarbosa, clarisse\}@inf.puc-rio.br, rprates@dcc.ufmg.br
}

\begin{abstract}
This paper presents Manas, a Semiotic Engineering epistemic tool for the design of collaborative systems (CoSys) whose aim is to expand the designers' knowledge and awareness of their influence on groups and group dynamics. Manas has been developed to help designers represent their conception of computer-mediated communication and reflect upon some of its potential social effects, springing from user-system interaction, as well from user-user interaction (through the system). The paper illustrates how Manas can lead designers to reflect upon both the design problem and its proposed solution(s), which allows them to make more conscious decisions. Increased knowledge and awareness should then enhance the quality of CoSys design.
\end{abstract}

Keywords: Semiotic Engineering, Collaborative Systems, Online Communities, Design Models, Computer-Mediated Communication, Social Aspects of HCI.

\section{Introduction}

Collaborative systems (CoSys) support and enable human interaction online. CoSys allows users to communicate not only with the system, but also, and mainly, with each other, through the system. The purpose of interaction varies widely, from working together, to exchanging personal and professional experiences, or just having fun. According to this broad definition, computer-supported cooperative work (CSCW), communities of practice, health support communities and games are all examples of CoSys.

For the last 20 years, researchers have pointed out the complexity involved in designing collaborative systems [1], [12]. One of the main aspects involved in the use of CoSys, which should be carefully considered during the design process, is the social effect caused by the system on groups or communities of users [8],[19]. A number of tools, models and frameworks have been proposed to support CoSys designers. They are usually task-based, allowing designers to analyze or describe, at different levels of abstraction, which tasks can be performed by all group members and how tasks relate to each other. Such is the case with Groupware Task Analysis 
(GTA) [22], ConcurTaskTrees (CTT) [14], Collaboration Usability Analysis (CUA) [16], and 3C Collaboration Model (3C) [10]. In all of these, communication among group members is represented implicitly or in necessary association with tasks.

In this paper, we present Manas [3], a Semiotic Engineering [6] epistemic tool to support designers in representing and reflecting upon how users can or should communicate with each other (USU communication) through CoSys. Manas separates communicative from task-related dimensions, and provides a design language in which to describe the envisaged USU communication. It also provides qualitative feedback on some of the potential social effects that USU design decisions may have on the group of users. By doing so, Manas can lead designers to reflect upon both the problems being handled and their proposed solution(s). Thus designers are prompted at design time to take potential social impacts of the designed system into more careful consideration.

As a by-product of language description and model-based reasoning for providing feedback on design decisions, Manas traces the USU communication design rationale, a valuable asset for ulterior steps in the design process, as well as for system documentation, maintenance and online help design.

In spite of their widely recognized relevance, social aspects of CoSys design have not received as much support as needed, especially in the form of design tools. Although useful general recommendations (e.g. sociability guidelines [19]) are available, they do not necessarily help designers understand or perceive how they should be applied when conflicting indications are met, or what implications are brought about by choosing one guideline to the detriment of others. Previous approaches such as Action Workflow [13], DEMO [7], Milan Conversation Model [5], and the BAT model [11], for instance, had already brought communication among group members to the center of designers' attention. However, they focused almost exclusively on the communicative actions and patterns made available at interaction time. The potential social consequences of choosing one or another were not explored. A paradigmatic example of a communication-centered perspective on CoSys design, The Coordinator [24] implemented a mapping of speech acts onto a workflow model, having the USU communication model subsume (or virtually stand for) other models involved in group interaction (task models, social models, coordination models, etc.).

Manas' main contribution is then to: (i) provide the representational means to describe the social dimensions of CoSys design decisions, isolating communication issues from tasks issues (but not having one subsume the other); and (ii) to provide qualitative feedback for such decisions, based on various theories about (or related to) interpersonal communication (e.g. semiotics [9][15], conversation and discourse analysis [4] and speech act theory [20][21][23]).

In section 2 we illustrate some of the social issues associated to design choices in an online discussion forum, so that the reader can see concrete examples of the range of problems Manas can deal with. Then in section 3 we present a brief overview of Manas' structural and functional profile, with a more detailed description of its design language. In section 4 we show how Manas can help designers deal with some of the issues raised in section 2. And finally, in section 5, we conclude the paper by discussing Manas' perceived value and by presenting our next steps in this research. 


\section{Social Effects of an Online Forum}

Online forums provide very popular examples of the kinds of activities and interaction supported by CoSys. In order to illustrate the purpose of Manas and the benefits that designers can gain from using it as a design tool, we will use an online forum especially developed to support long-term scientific discussions of our research group - OriOn $\mathrm{V}^{1}$. Compared to standard online forums (e.g. MSN Groups), the most salient difference introduced by OriOn is that when users post messages they qualify it by a rhetorical marker that binds it to the superordinate message it is supposed to respond to. In MSN Groups, for example, you find messages structured in a recursive subordination chain that we can represent like this ${ }^{2}$ :

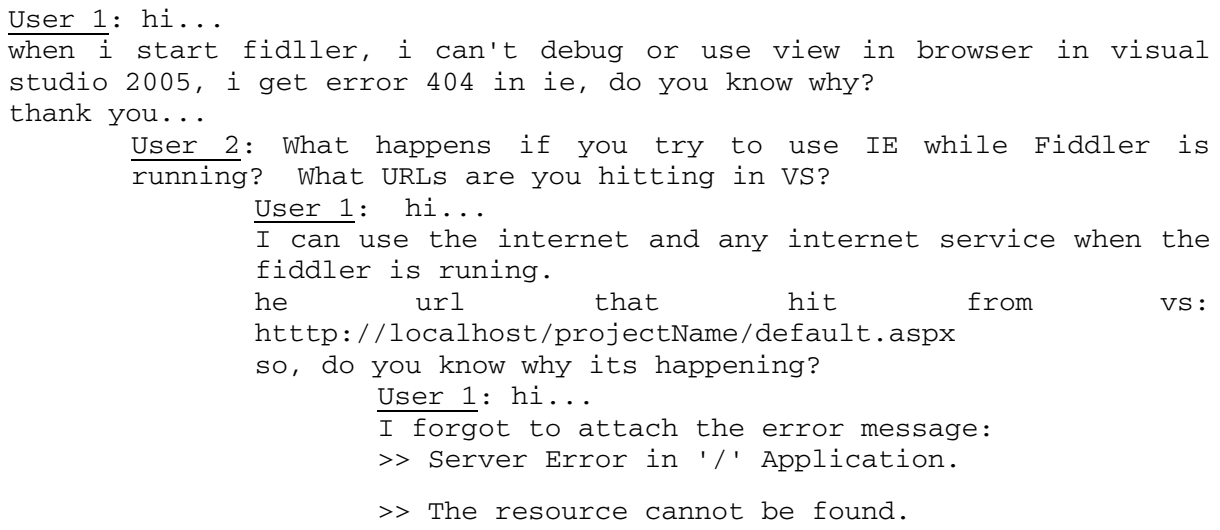

In OriOn the above conversation would be structured in a rhetorical chain (i.e. a chain of messages whose relations with each other are rhetorical, such as question-answer, statement-elaboration, statement-concession, etc.) built by users themselves. So, for example, users might choose to prefix their messages with question-answer and conjunction markers like this:

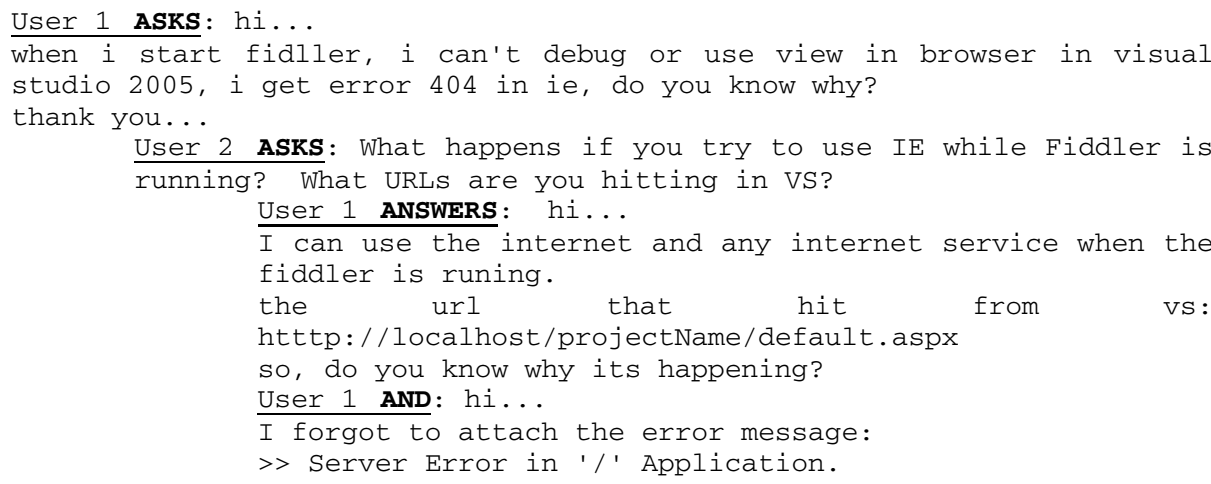

${ }^{1}$ OriOn V1 is the 1 st version of the forum (now in its 2 nd). In the remainder of the paper "OriOn" always refers to OriOn V1.

2 The anonymized conversation in this example has been extracted from a public MSN Group in January 2007. 
>> The resource cannot be found.

The value of OriOn's rhetorical structuring is that it readily characterizes the above dialogue as an open conversation: a question has been asked, and another question was asked in response (requesting further information); the requested information has been given, in two subsequent messages (ANSWER + ADDENDUM). Especially in long-term scientific discussions, where the structure of arguments is elaborate typically including concessions, illustrations, elaborations, etc. - these markers can support text summarization or visual (abstract) representations of the state of discussions, helping discussants address open questions, identify lively debates, spot the discussants who are leading conversations here and there, and so on. This can make discussions more agile, efficient and productive.

However, after five years of regular use, and a number of redesigns (all keeping with the rhetorical markers, but none including the expected summarization and visualization facilities yet), two related phenomena were observed. First, non-directed questions like the ones above (i.e. questions that were not directed to one particular discussant of the group, but to all) often took longer to be answered, because everybody passed the baton to everybody else. Locks of this type were usually resolved outside OriOn, in face-to-face conversations or emails. Second, questions could be explicitly directed to one or more discussants (e.g. "Hi, Albert and/or Amelia - when I start a fiddler I get this error message [etc.]. Do you know why?"). This second alternative could be more successful than the first, the answer being given more quickly. However, regarding the top-level issue that OriOn's designers were trying to address - a more accurate representation of the state of discussions in order to make them more agile, efficient and productive - this was a "work around", rather than a solution. Why? Because when summarizing or visualizing texts based on structural elements, there would be no representation for the fact that "Albert" and "Amelia" were the expected respondents of that particular request.

At closer examination, we saw that the problem with OriOn's structuring in this case is that, although it is perspicuous enough to represent rhetorical relations and help users distinguish between pending vs. complete argumentations, for example, an important item was missing: the identification of addressed listeners. OriOn's design, like that of most discussion forums, conceives that messages posted in a forum are for all to see and for anyone to answer. Although this is true, there is an important distinction in the semantics of for all to see that designers missed: that, just like in any face-to-face group discussion, some parts of the conversation may take place between "Albert" and "Amelia", but they are not private - they are public. And because they are public, everybody is welcome to contribute, but it would be impolite not to recognize that the conversation is going on between the two. For example, it would be in principle impolite to suggest changing subject right after Amelia asks Albert a question, not giving him the opportunity to answer. This suggestion, in face-to-face situations, would very probably be interpreted as an equivalent of one of the following: "This conversation has lasted long enough.", or "Amelia, you should not have asked this question.", or "Let's help Albert not lose face by having to answer this question."

The cost of missing this sort of scenario at design time can be charged later in the currency of social relations among users, group discussion dynamics, or software redesign and upgrades. For instance, if no one had answered User 1's question, he 
could have perceived it as "No one knows the answer to my question.", or "I was expected to know how to solve this.", or he could even have taken it to a more personal side "No one cares about me or my problems.". The social effects of perceived impoliteness can be very undesirable: users may be discouraged to reengage in discussions, users may inadvertently be caught up in social quid pro quos, etc. In some kinds of groups, more than others - for instance in health support online communities - these effects can be disastrous. The point for CoSys design is that the system (Orion, in this case) does not support users in "managing" their level of politeness, to the extent that they can often be inadvertedly impolite with others. Manas thus sets out to help designers oversee this kind of issue at design time, rather than only facing it in longitudinal evaluation studies after the system is implemented.

\section{Manas - An Epistemic Tool}

Manas is an epistemic tool based on Semiotic Engineering [6]. In this semiotic theory of HCI, user-system interaction is viewed as a particular kind of computer-mediated metacommunication (communication about communication). In it, the designer (or the spokesperson of the design team) sends users a message about how they can or should interact with the system in order to achieve a certain range of goals and experiences which it has been designed to support. This message tells users the designer's vision, including her understanding of who the users are, what they need or wish to do, how they prefer to do it, and why. In the context of CoSys, it also tells them the designer's understanding of their communicative needs, namely: who the interlocutors of the group communication processes are; who they can communicate and interact with; about what; for what purposes; and how.

In order to support designers in conceiving better metacommunication messages the theory offers them a variety of epistemic tools. These are tools that allow them to leverage their knowledge about the situation at hand, the problems involved in it, their solution, as well as their expected impacts on users. They are not tools that present ready-made solutions (e.g. patterns) for designers to choose and apply. Rather, they assist designers in carefully elaborating the essence of their metacommunication message with respect to the users' communicative needs. Manas [3], which is the result of research started by Prates [17], [18] and extended by Barbosa [2], is one such tool. It helps designers to describe their vision for the communication among users, and gives them feedback on the social effects of design descriptions.

Manas embodies a conceptual architecture model for CoSys design-support tools comprising the following components: (a) a design language, L ComUSU, in which to describe USU communication; (b) an interpreter of L-ComUSU, whose output (or interpretation) is a model of USU communication, m-ComUSU, plus feedback assertions (the analog of warnings issued by programming language interpreters); and (c) an annotated derivative of $\mathrm{m}$-ComUSU, which is the equivalent of the design rationale. Next we present Manas and each of its components. Manas' architecture model is depicted in Figure 1. 


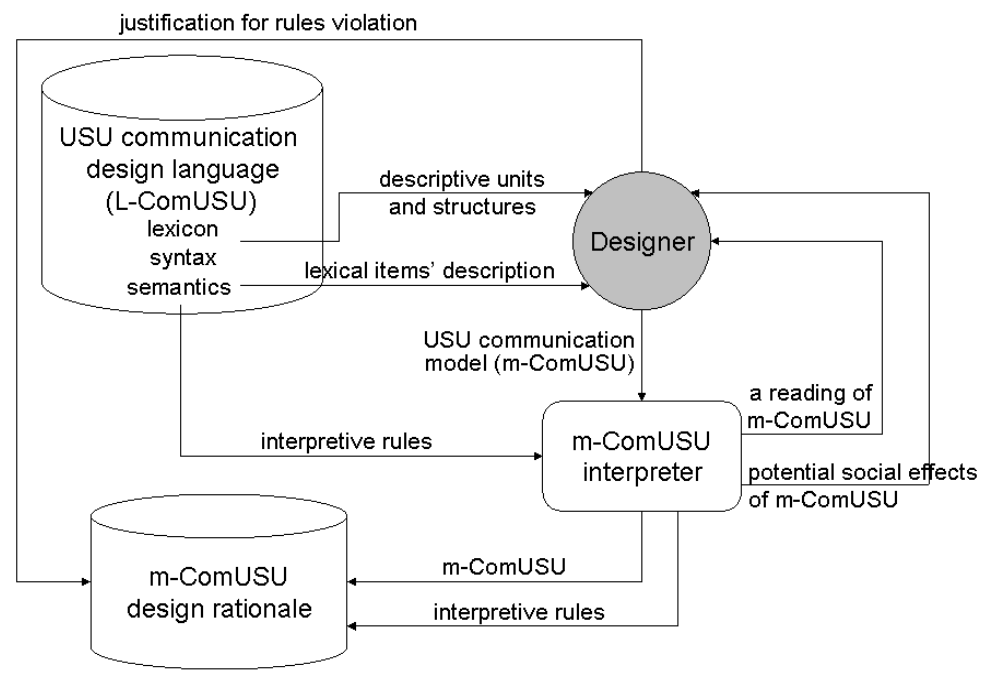

Fig. 1. Manas' conceptual architecture

The underlying interpretive rules that give consistency to Manas, binding LComUSU semantics, m-ComUSU configurations, the detection of potentially problematic design decisions, and the structure of annotations on L-ComUSU representing the design rationale, are mostly drawn from theory. Conversation and discourse analysis [4], speech act theory [20][21][23], and Semiotic Engineering [6] are the main sources [3].

L-ComUSU defines lexical items and syntactic rules. Lexical items typically represent communication elements, whereas syntactic rules define how such elements relate to each other. Elements and relations are qualified by attributes. The possible values that attributes may take are also defined by L-ComUSU. The semantics of the language constitutes a cohesive abstract model of CoSys communication and associated social effects, and is encoded in Manas' interpreter. Thus, a full LComUSU description of the designer's vision is interpreted as an instance of the abstract model that constitutes the semantics of the design language. Figure 2 depicts the lexical and syntactic components of the underlying L-ComUSU model.

Users' communication must be defined in terms of communicative structures which are composed by communicative acts and involve interlocutors. A communicative act may be a speech (a speaker's utterance to one or more listeners) or a conversation (speakers and listeners alternate roles, producing various utterances). Commmunicative acts achieve a goal or purpose. In speeches these are associated with individual utterances, whereas in conversations a goal or purpose should be shared by all interlocutors. All the components in Figure 2 are types, not tokens, that is, they describe what can be represented by L-ComUSU, but do not depict any specific communicative situation. There are many possibilities for instantiating m-ComUSU models, depending on which components are chosen by designers, and which values are assigned to them. Hence the type-level representations. 


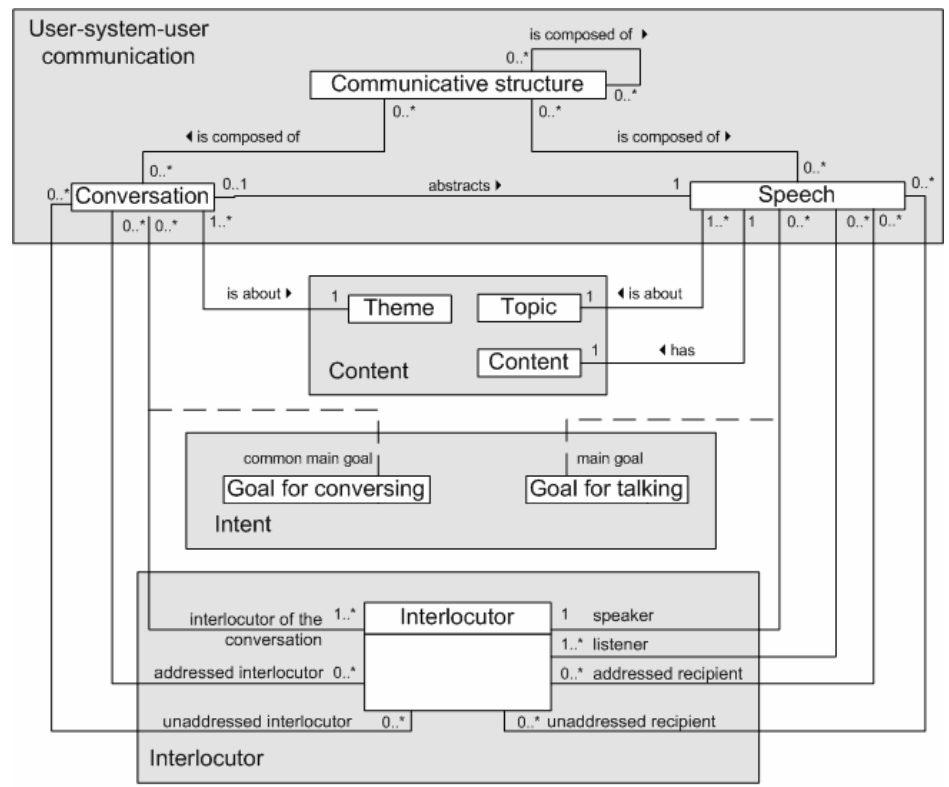

Fig. 2. Lexical and syntactic components of the L-ComUSU model

When describing interlocutors the designer must inform whether they are ratified or not, addressed or not. A ratified interlocutor is one that is perceived by others as authorized to participate in the communication. Ratified interlocutors may be addressed or not-addressed. Addressed interlocutors are those to whom the communicative act is being directed, whereas not-addressed interlocutors are the others participating in that same communication process. For instance, in a chat room all users are ratified interlocutors. If in that chat room User 1 says: "User 2, do you want to play a game now?", then User 2 is the addressed interlocutor of User 1's communicative act, whereas all the other participants of the chat room are not-addressed interlocutors.

For each of these elements, the designer must also define a series of attributes. Among other things, attributes indicate the following: whether the element will be explicitly represented in the system or not; the possible values it may assume; who is responsible for determining its value (user, system or both); if it is a mandatory value or not; if it has a default value, and which value this is (if there is one).

The interpretive rules that comprise the semantics of L-ComUSU embody specialized knowledge about the social implications of specific model configurations. In the next section we will illustrate how Manas as a whole support design decisions relative to social aspects of communication.

\section{How Manas Supports Designers}

In section 2 we illustrated some of the social impacts that design decisions underlying an online forum could have on its users. In this section, we illustrate how Manas 
could have supported OriOn designers at design time. In order to do so, we describe portions of the system model, and how Manas could have led designers to think about some of the social effects of the system upon the group of users. For each example we represent: (a) the Design Choice; (b) the Social Issues involved in the design choice; and (c) the Social Effects that the design choice can have on users. The Design Choice is a "read out" (represented in natural language) of L-ComUSU configurations resulting from the designer's decisions. The Social Issues are classes of communicative phenomena that Manas can model. Finally, the Social Effect is an explanatory natural language text Manas presents to the designer about the social impact a design choice (described in L-ComUSU) may have. So, we see that the gist of Manas is to associate qualitative assessments (namely, the interpretation of social impacts) to linguistic descriptions of CoSys design choices about how users can or should communicate with each other. The descriptive language is, of course, LComUSU. In Figure 3 we show a visual representation of the structure of a description in L-ComUSU. First, all elements are created (without further details), and then for each created element we define all attributes that compose their individual descriptions.

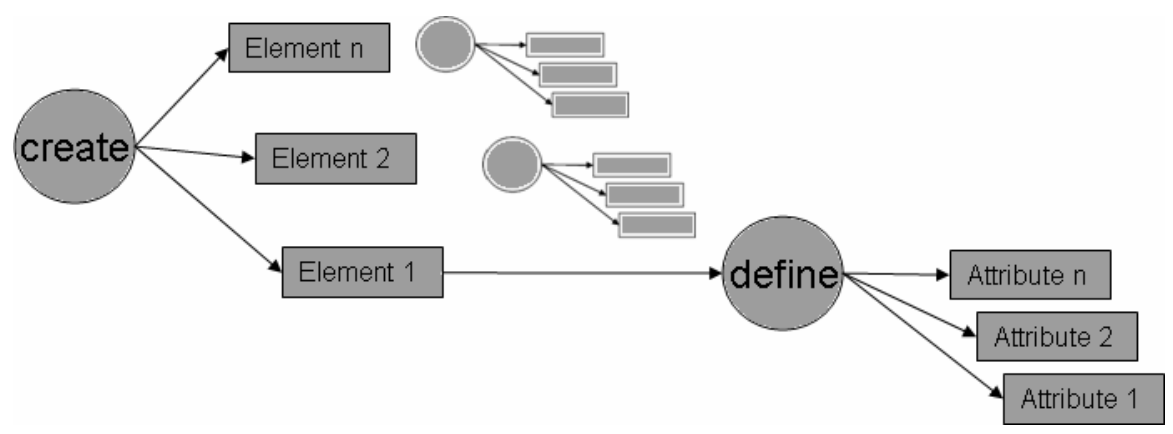

Fig. 3. The structure of L-ComUSU descriptions

The passage below is a partial description of OriOn defining aspects of how users communicate through the system. The description is in the form of natural language sentences paraphrasing constructs of L-ComUSU ${ }^{3}$.

In this system, any group member is an interlocutor, and there is only one communicative act - a discussion. All interlocutors (speakers and listeners) are explicitly represented in the design model. The system sets them as addressed interlocutors. Not-addressed listeners are not explicitly represented in the system. Interlocutors may engage in conversations about any theme they like. Both the theme and purpose of conversations are explicitly represented in the system, and their value is defined by the user at interaction time.

\footnotetext{
${ }^{3}$ An extract of the description written on Manas' design language would require an explanation of its syntax which is beside the point of this paper.
} 
Based on this partial description Manas is then apt to provide feedback on its potential social effects. These may affect the group's privacy, codes of politeness and communication efficiency.

Design Choice ${ }^{4}$ : Explicitly represent the conversation's purpose.

Social Issues pointed by Manas: politeness and communication efficiency

Social effect: On one hand, explicitly representing the communication's purpose may make it clearer and more perspicuous. On the other hand, some purposes may not be pleasant to the listener and may put the speaker in an awkward or embarrassing position.

Based on this potential social effect, the designer may come to the conclusion that although explicitly representing the purpose of the communication may contribute to having more precise or focused discussions, this could also cause problems. For instance, one member of the group could sound impolite to another if among the possible purposes of communication were the equivalent of this: "Dissuade interlocutor from a bad decision". Prompted by the comment on the "social effects" of her decision, the designer may explore different alternatives. For example, one would be to give users the option of not informing the purpose of communication. Another would be to allow them to introduce their own phrasing of such purpose. In both cases, users would be trading communication efficiency for politeness and good social relations with others.

Design Choice: Explicitly represent the addressed listeners of the conversation, but not the not-addressed listeners.

\section{Social Issues pointed by Manas: communication efficiency}

Social effect: Every communication is addressed to a set of listeners, but in a specific context there may also be ratified not-addressed listeners. In that case, in order to successfully achieve the communication's purpose it is important to explicitly identify these listeners. When they are not explicitly represented, users may use alternate system resources to distinguish between addressed and not-addressed listeners. For instance, the speaker may identify addressed listeners as part of the topic or content of the communication (if they are available). In some cases, the distinction between addressed and not-addressed listeners may be clear in the context in which the system is being used.

Although all users are always addressed listeners of every discussion in OriOn, that is not how our research group actually interacts. While some discussions involve all members, others involve only specific subgroups. "Involving" should not be taken as a matter of authorization (because there are no secret scientific discussions going on), but rather as a matter of interest or competence. So, for example, a discussion about mobile devices is not likely to be of interest or competence for group members specializing in semiotic theories. Thus, OriOn users have chosen to represent addressed (interested and competent) users as part of the title of the discussion (as shown in Figure $4^{5}$ ).

\footnotetext{
${ }^{4}$ L-ComUSU equivalent.

${ }^{5}$ Figure has been translated to English and anonymized.
} 


\begin{tabular}{|ll|}
\hline CourseI - Final Test & amanda \\
\hline CourseI - Interaction Models & amanda \\
\hline LINKS \& Readings - Suggestions & amanda \\
\hline Lucy - Dissertation & lucy \\
Lucy - Individual study & amanda \\
\hline Ann - Thesis Research & amanda \\
\hline Gender in HCI & robert \\
\hline Interaction Model & amanda \\
\hline ORION - Suggestions & mary \\
\hline RESEARCH - Reflections and Discussions & amanda \\
\hline Evaluation Research (Amanda, Paula, Chris) & amanda \\
\hline Alexandra, Amanda, Mathew - Articles 2005 & alexandra \\
\hline Interactive TV - Julie and Henry & amanda \\
\hline Sophie - Individual Study & sophie \\
\hline Linda and Amanda - Book chapter & amanda \\
\hline
\end{tabular}

Fig. 4. OriOn with members listed on discussion topics

If the designer had been warned about this situation at design time, she might have been able to perceive that even though the group was a cooperative and cohesive one, it could be better not to describe all group members as addressed, but rather let users say who is directly involved (addressed) in a particular discussion, and thus expected to make contributions. One of the implications of not allowing users to distinguish between addressed and not-addressed listeners becomes even clearer when we take into consideration the next potential social effect, which Manas would also indicate.

Design Choice: Addressed listeners are determined by system.

\section{Social Issues pointed by Manas: privacy}

Social effect: The system is not being designed to (fully) support private conversations. If the listeners are determined by the system, a user can only succeed in having private conversations with other users, if the intended listeners coincide with the ones that have been determined by the system. If the designer intends to allow users to communicate privately with each other, then users should be the ones to determine who the listeners of their communicative act are.

As the designer thinks about these social effects, she may realize that by explicitly representing addressed and not-addressed listeners, she may also provide the group with more ability to express the privacy of subgroups. She could then consider if it would be interesting to make a distinction between public discussions (all could listen and speak), private discussions taking place at a public space (all could listen, but not 
all would be expected or allowed to speak), and private discussion (only a subgroup would be able to listen and speak).

Design Choice: No explicit representation for not-addressed listeners.

Social Issues pointed by Manas: communication efficiency

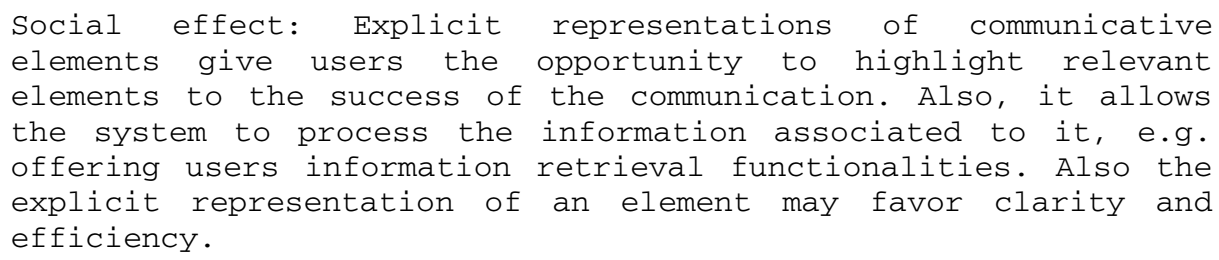

This effect pointed by the system could provide designers with more information regarding costs $v s$ benefits of explicitly distinguishing between addressed and notaddressed users. It points out that by making this distinction the system could use it to provide new visualizations and information to the users. For instance, they might be able to see, quickly, who is working on what. This new possibility could support some of the group's characteristics valued by its members, such as cohesiveness and interaction.

The explanations provided by Manas do not intend to tell designers what the appropriate decision is, its goal is to call their attention about the potential social effects caused by their decisions regarding users' communication through the system. By leading designers to reflect upon these situations and issues Manas may encourage them to make clearer decisions about what would be relevant for the group and/or feasible for the development team. For instance, at one point the designers might realize that they did not have enough information about the group's intent or needs (e.g Is it important to be able to have public and private communications?). In that case, the need to talk more to users would have been made clear. Designers could even discuss with them the pros and cons of the issue, based on Manas' feedbacks about design alternatives.

It is important to point out that the situations and social effects identified by Manas are not prescriptive, that is, they are not intended to dictate the best solution, but rather to lead designers to consider the issues raised in their own context. In the OriOn examples, we have discussed social aspects of communicative situations faced by a cohesive and cooperative research group. In other contexts, such as when the idea is to foster competition among group members, or design a generic system that could work for any group, the effects pointed out by Manas could (and probably would) entail different considerations and decisions.

\section{Discussion and Conclusion}

In this paper we have presented Manas an epistemic tool that supports designers in defining the USU communication of a CoSys, and provides them with feedback on the social effects their decisions may have on the users' group. Manas can be defined as context separable, in the sense that it takes into account the combination of values of the communicative elements, their relations and attributes in identifying the potential social impacts of the system, but not the domain or context in which the 
system will be used. Thus, Manas does not aim at indicating a solution to the designers, but rather at pointing out how their design choices may impact users' experience, in respect to social aspects, such as privacy, politeness and communication efficiency. By informing the designer on possible effects, Manas prompts them to consider these effects in the context at hand, reflecting upon their proposed solution, and thus, making a more conscious decision on the USU communication of the system being conceived.

Manas is not the first proposal to support designers during the design of collaborative systems. Guidelines and models have been proposed and used by CoSys designers. However, Manas presents an innovative and original approach that differs from the existing proposals in relevant aspects. First of all, like the existing models it offers a representation in which to describe relevant aspects of the CoSys being conceived. However, different from them it provides designers with feedback based on their design choices pointing to social impacts they may have on users' experience.

In comparison to task models [10][14][16][22], it has a significant difference as it decouples communication from tasks. By doing so, it extends the contexts in which it can be used by designers to CoSys in which tasks are not the focus, such as health support online communities. Other models have focused on communication $[5][7][11][13][24]$. In relation to them, Manas brings a new level of abstraction in which to consider communication, since it does not define communicative patterns that constrain users' communicative acts, but rather the types of communicative acts that may be available to users. This higher level approach allows the designer to characterize communication and reflect upon it, not only as an exchange of content between users, but as a socio-cultural activity.

Finally, Manas is different from the other models described since it is based on an HCI theory, Semiotic Engineering [6]. The advantage of being grounded on this theory is that the proposal takes into account not only the step of the design process it is aimed at, but also its characterization of the human-computer interaction phenomenon as a designer to user metacommunication. Manas makes it clear to designers that their decisions are conveyed to users through the system and influences the users experiences. Therefore, Manas can also help designers understand better their own design activity.

Since Manas is grounded on an HCI theory, it has a scientific contribution to HCI, and particularly to Semiotic Engineering theory. In a scientific research, theory and practice must complement each other and provide input to each other. Hence, as Manas is used, empirical data on its use and how it influences the design process can be collected. This data can then be analyzed and used to support (or not) the Semiotic Engineering premises in which Manas was grounded.

Manas proposed support to designers has been initially evaluated through a prototype system developed and in two case studies [3]. The prototype was developed in Prolog, and its use required knowledge of L-ComUSU lexical elements, their attributes and syntax. The first case study was an analytical evaluation which involved describing an existing CoSys using L-ComUSU to verify whether all communicative acts encoded in the system could be described by the language. The second case study aimed at assessing whether other designers not involved in the Manas research would be able to understand it and use it. In this case study, the participants were graduate students who knew Semiotic Engineering, and they were asked to describe portions of 
OriOn using L-ComUSU. Both case studies provided positive indicators on the LComUSU expressive power, on how it may be used and its usefulness to designers. The next step in this research involves the development of a usable system based on Manas that can be used by designers in conceiving their systems. As the system is used data on how it supports the designer, their perception of its usefulness and how it is integrated to existing design processes can be collected and used to evaluate Manas and define the next steps in this research.

One relevant point to notice is that Manas' feedback is on the social impact of the CoSys being designed. However, social aspects are culturally dependent. Thus, rules and social effects that are currently defined in Manas may not be applicable to other cultures different from the Brazilian culture, or maybe western culture. Thus, how to adapt Manas to CoSys being developed for other cultures or for an international audience must be investigated.

Acknowledgments. The authors thank participants of the initial evaluation of Manas for their contribuition. Clarisse de Souza thanks CNPq for a supporting her research and Clarissa Barbosa thanks CAPES and CNPq for scholarships received during her $\mathrm{PhD}$.

\section{References}

1. Ackerman, M.: The Intellectual Challenge of CSCW: the gap between social requirements and technical feasibility. Human-Computer Interaction 15(2), 181-203 (2000)

2. Barbosa, C.M.A.: MetaCom-G*: especificação da comunicação entre membros de um grupo. MSc Dissertation. Computer Science Department, PUC-Rio, Brazil (2002)

3. Barbosa, C.M.A.: Manas: uma ferramenta epistêmica de apoio ao projeto da comunicação em sistemas colaborativos. PhD Thesis. Computer Science Department, PUC-Rio, Brazil (2006)

4. Brown, P., Levinson, S.C.: Politeness: some universals in language use. Cambridge University Press, Cambridge (1987) (first published in 1978)

5. De Michelis, G., Grasso, M.A.: Situating conversations within the Language/Action Perspective: the Milan Conversation Model. In: CSCW'94. Proceedings of the 1994 ACM conference on Computer supported cooperative work, Chapel Hill, North Carolina, USA, October 22-26, 1994, pp. 89-100. ACM Press, New York, NY (1994)

6. de Souza, C.S.: The Semiotic Engineering of Human-Computer Interaction. The MIT Press, Cambridge, MA (2005)

7. Dietz, J.L.G.: DEMO: towards a discipline of organisation engineering. European Journal of Operational Research 128(2), 351-363 (2001)

8. Dourish, P.: Where the Action Is. The MIT Press, Cambridge, MA (2001)

9. Eco, U.: A Theory of Semiotics. Indiana University Press, Bloomington (1976)

10. Fuks, H., Raposo, A.B., Gerosa, M.A., Lucena, C.J.P.: Applying the 3C Model to Groupware Engineering. Monografias em Ciência da Computação. PUC-Rio Inf.MCC01/04. Computer Science Department, PUC-Rio, Brazil (2004)

11. Goldkuhl, G., Lind, M.: The Generics of Business Interaction - emphasizing dynamic features through the BAT model. In: LAP 2004. Proceedings of the 9th International Working Conference on the Language-Action Perspective on Communication Modeling, New Brunswick, NJ, June 2-3, 2004, pp. 15-40. Rutgers University, New Jersey, USA (2004) 
12. Grudin, J.: Groupware and Social Dynamics: eight challenges for developer. Communications of the ACM 37(1), 92-105 (1994)

13. Medina-Mora, R., Winograd, T., Flores, R., Flores, F.: The Action Workflow Approach to Workflow Management Technology. In: CSCW'92. Proceedings of the 1992 ACM Conference on Computer-supported Cooperative Work, Toronto, Ontario, Canada, October 31 - November 4, 1992, pp. 281-288. ACM Press, New York, NY (1992)

14. Paternò, F.: The ConcurTaskTrees Notation. In: Paternò, F. (ed.) Model-based Design and Evaluation of Interactive Applications, Springer, London, UK (1999)

15. Peirce, C.S.: Collected Papers of Charles Sanders Peirce. In: Hartshorne, C., Weiss, P. (eds.) Collected Papers of Charles Sanders Peirce, vol. 1-8, pp. 1-8. Harvard University Press, Cambridge, MA (1958)

16. Pinelle, D., Gutwin, C., Greenberg, S.: Task Analysis for Groupware Usability Evaluation: Modeling Shared-Workspace Tasks with the Mechanics of Collaboration. ACM Transactions on Computer-Human Interaction 10(4), 281-311 (2004)

17. Prates, R.O.: A Engenharia Semiótica de Linguagens de Interfaces Multi-usuário. $\mathrm{PhD}$ Thesis. Computer Science Department, PUC-Rio, Brazil (1998)

18. Prates, R.O, de Souza, C.S.: Towards a Semiotic Environment for Supporting the Development of Multi-user Interfaces. In: CRIWG '98. Proceedings of the Fourth CYTED-RITOS International Workshop on Groupware, Búzios, RJ, Brazil, September 911, 1998, pp. 53-67 (1998)

19. Preece, J.: Online Communities: Designing Usability, Supporting Sociability. John Wiley \& Sons, Chichester, UK (2000)

20. Searle, J.R., Vanderveken, D.: Foundations of illocutionary logic. Cambridge University Press, Cambridge (1985)

21. Searle, J.R.: Conversation reconsidered. In: Parret, H., Verschueren, J. (eds.) (on) Searle on conversation, pp. 137-148. John Benjamins, Amsterdam (1992)

22. van der Veer, G.C., van Welie, M.: Groupware Task Analysis. In: Tutorial Notes for the CHI'99 workshop Task Analysis Meets Prototyping: towards seamless UI Development, Pittsburgh, PA, USA, May 16, 1999 (1999)

23. Vanderveken, D.: Illocutionary logic and discourse typology. Revue Internationale de Philosophie 55(216), 243-255 (2001) (special issue: Searle, with his replies)

24. Winograd, T., Flores, F.: Understanding computers and cognition: a new foundation for design. Ablex Publishing, Norwood, NJ (1986) 